\title{
Study of Silver Nanoparticles Sensitized Fluorescence and Second-Order Scattering of Terbium(III)-Pefloxacin Mesylate Complex and Determination of Pefloxacin Mesylate
}

\author{
Aiyun $\mathrm{Li}^{1}$ and Zhiqiang Song ${ }^{2}$ \\ ${ }^{1}$ Experimental Center of Fundamental Theories, Shandong Sport University, Jinan 250102, China \\ ${ }^{2}$ Department of Physical Education, Shandong Sport University, Jinan 250102, China \\ Correspondence should be addressed to Aiyun Li; aiyunli_2013@163.com
}

Received 30 December 2013; Accepted 9 April 2014; Published 6 May 2014

Academic Editors: F. Márquez, G. Morales, and F. Scala

Copyright ( $\odot 2014 \mathrm{~A}$. Li and Z. Song. This is an open access article distributed under the Creative Commons Attribution License, which permits unrestricted use, distribution, and reproduction in any medium, provided the original work is properly cited.

$\alpha$-Keto acid of pefloxacin mesylate (PFLX) can form the complex with Terbium(III). The intramolecular energy from PFLX to Terbium(III) ion takes place when excited, and thus Terbium(III) excited state is formed and then emits the characteristic fluorescence of Terbium(III), locating at 490,545, 580, and $620 \mathrm{~nm}$. The second-order scattering (SOS) peak at $545 \mathrm{~nm}$ also appears for the complex with the exciting wavelength of $273 \mathrm{~nm}$. When the silver nanoparticles are added to the system, the luminescence intensity at $545 \mathrm{~nm}$ greatly increased. So, with the adding of nanoparticles to the Terbium(III)-PFLX complex, not only is the intramolecular energy promoted but also the SOS intensity is enhanced. The experimental results show that it is the silver nanoparticles with certain size and certain concentration which can greatly enhance the fluorescence-SOS intensity, and the relative intensity at $545 \mathrm{~nm}$ is proportional to the amount of PFLX. Based on this phenomenon, a novel method for the determination of PFLX has been developed and applied to the determination of PFLX in capsule and serum samples.

\section{Introduction}

In recent years, researches on noble metals nanoparticles have got considerable attention in chemistry and physics [1-3] especially silver nanoparticles, which exhibit an enhancement of some potential properties including electrical conductivity [4], catalysis [5, 6], magnetic and optical polarizability [7], photonic technologies [8-11], and antimicrobial activity in surface-enhanced Raman scattering (SERS) [12]. Particle size may influence the physical properties of silver nanoparticles [13-15]. With the progress of nanotechnologies and the spectrum theories, more studies have been attracted to the luminescence of the role of silver nanoparticles $[16,17]$.

Terbium ions have unique fluorescent properties when complexed with organic ligands. The strong ion emission of these complexes originates from an intrachelate energy transfer from the triplet state of the ligand to the excited energy levels of the lanthanide ion. Methods for the determination of several organic compounds, which serve as energy donors to Terbium ions, have been developed [24].
Ofloxacin (OFLX), ( \pm )9-fluoro-2,3-dihydro-3-methyl10-(4-methyl-1-piperaziny)-7H-oxo-7H-pyrido[1,2,3-de]1,4-benzoxazine-6-carboxylic acid (as shown in Figure 1), is one of the third-generation members of quinolone synthetic antibiotics, with a broad spectrum of activity against Gram-positive and Gram-negative bacteria [25, 26]. It is widely used in therapies against inflammation [27]. The drug's effect is concentration dependent and its antibacterial effect is closely related to its plasma concentration.

Pefloxacin mesylate (PFLX), 1-ethyl-6-fluoro-1, 4-dihydro-7-(4-methylpiperazin-1-yl)-4-oxoquinolone-3-carboxylic acid (as shown in Figure 1), is a fluoroquinolone antibacterial agent. It is used for the treatment for diseases of the skin and various kinds of urinary tract infections [28] and has been widely applied in clinical medicine. Determination methods for PFLX include spectrofluorometry [24, 29, 30], HPLC [31], TLC-fluorescence [32], and capillary electrophoresis $[33,34]$. But using the silver nanoparticlessensitized fluorescence and second-order scattering (SOS) for the determination of PFLX has not been reported. 


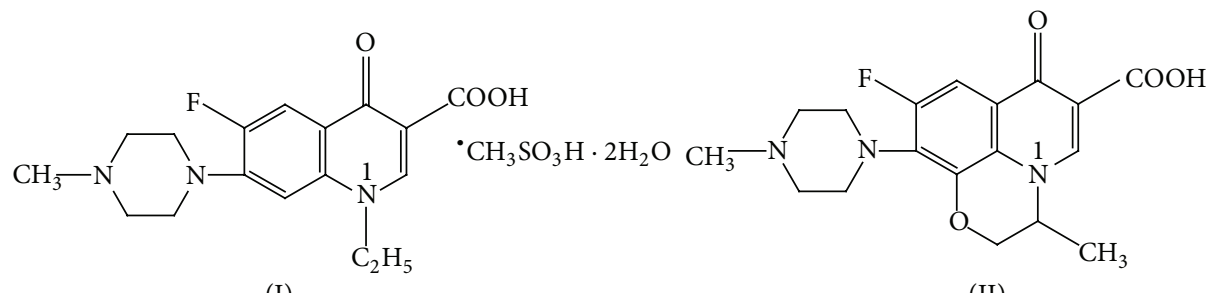

(I)

(II)

FIgure 1: Structural formulae of the PFLX (I) and OFLX (II).

In this paper, the influence of silver nanoparticles on the SOS and fluorescence of Terbium(Tb)(III)-PFLX complex is studied through using the SOS and fluorescence spectrum. The results show that the size and concentration of nanoparticles can greatly affect the fluorescence-SOS intensity of the complex. Based on this phenomenon, a novel method has been developed for the determination of PFLX, and the determination comparison between PFLX and OFLX is also proposed.

\section{Material and Methods}

2.1. Apparatus. A transmission electron microscopy (TEM) image of the silver nanoparticles was acquired using a Hitachi H-600 (Japan) transmission electron microscope. A Shimadzu RF-5301 PC spectrofluorometer (Japan) was used for fluorometric and SOS measurements. All absorption spectra were recorded with a Cintra 10e UV-vis spectrophotometer (GBC). A 420A plus pH meter (Orion Research Inc) is used to measure $\mathrm{pH}$ of the solutions. All reagents were of analytical reagents grade and doubly distilled water was used throughout.

Stock standard solution $\left(1.0 \times 10^{-3} \mathrm{M}\right)$ of PFLX and OFLX (Institute of Medical Biotechnology, Beijing, China) was prepared by dissolving them in proper solvent (dilute acid or alkali) and then was diluted to the desired concentration with water.

2.2. Reagents. A standard stock solution of the $\mathrm{Tb}(\mathrm{III})$ ion $\left(1.0 \times 10^{-2} \mathrm{M}\right)$ is prepared by dissolving $934.5 \mathrm{mg} \mathrm{Tb}_{4} \mathrm{O}_{7}$ in $15 \mathrm{~mL} \mathrm{HCl}(12 \mathrm{M})$ at $100^{\circ} \mathrm{C}$ and evaporating the solution to be almost dry; it is then diluted to $500 \mathrm{~mL}$ with water.

The preparation of the silver colloids followed the same procedure as originally proposed by Lee and Meisel [35]. $\mathrm{AgNO}_{3}$ is used as precursor of silver nanoparticles and sodium citrate is used as both reducing and protecting reagent. A concentration of $1.0 \times 10^{-4} \mathrm{M}$ colloidal solution is prepared in terms of the silver atoms. The morphology and size distribution of silver nanoparticles are obtained by a transmission electron microscopy (TEM) and were shown in Figure 2. The particles are almost spherical with a mean diameter of $42 \mathrm{~nm}$, and the silver nanoparticles had an absorption maximum at $420 \mathrm{~nm}$, which is consistent with the literature [35].

The drug content of five capsules is weighed, finely powdered, and mixed. The average mass per capsule can

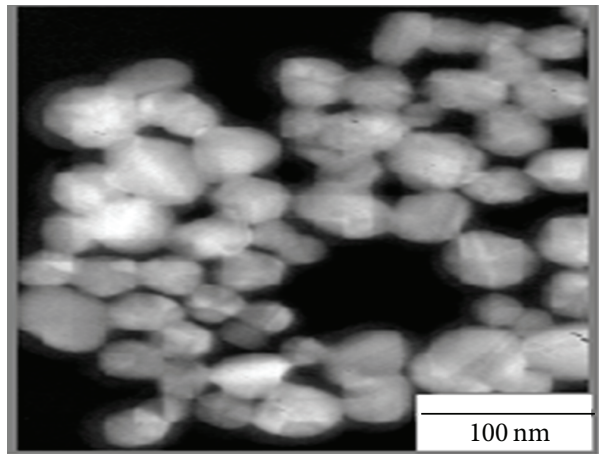

FIgURE 2: TEM image of the silver nanoparticles.

be determined. Transfer an accurately weighted amount of the powder equivalent to $200 \mathrm{mg}$ corresponding to one capsule into a $100 \mathrm{~mL}$ calibrated dark flask, in which the deionized water is added to dissolve the powder. The solution is then filtered so as to separate out the insoluble excipients. The desired concentration for the drug thus is obtained by accurate dilution with deionized water and the analysis is followed up as the general analytical procedure.

2.3. Procedures. As for a $10 \mathrm{~mL}$ test tube, $1.0 \mathrm{~mL}$ of $\mathrm{HAc}-\mathrm{NaAc}$ buffer solution, $0.2 \mathrm{~mL}$ of $1.0 \times 10^{-2} \mathrm{M} \mathrm{Tb}(\mathrm{III})$ ion solution, and an appropriate working solution or sample solution of PFLX, followed by $0.5 \mathrm{~mL}$ of $1.0 \times 10^{-4} \mathrm{M}$ silver nanoparticles are added. This mixture is diluted to $10 \mathrm{~mL}$ with water, mixed thoroughly, and stood for $25 \mathrm{~min}$.

The SOS intensity is recorded with the different excited wavelength from 220 to $400 \mathrm{~nm}$ and reached the maximum at $545 \mathrm{~nm}$ with $\lambda_{\text {ex }}=273 \mathrm{~nm}$. The enhanced SOS and fluorescence intensities are represented as $\Delta I=I-I 0$; here, $I$ and $I 0$ are the intensities of the system with and without PFLX or OFLX. All the data are obtained with $5.0 \mathrm{~nm}$ excitation and emission silt-widths.

\section{Results and Discussion}

3.1. UV-Vis Spectrum. UV-vis absorption spectra of the system (Figure 3) are recorded. It can be found that the absorption peaks at $275 \mathrm{~nm}$ and $323 \mathrm{~nm}$ for $\mathrm{Tb}$ (III)-PFLX complex increased along with adding silver nanoparticles to the system, and the absorption peak at $420 \mathrm{~nm}$ for the nanoparticles appeared. The results indicate that there exist 


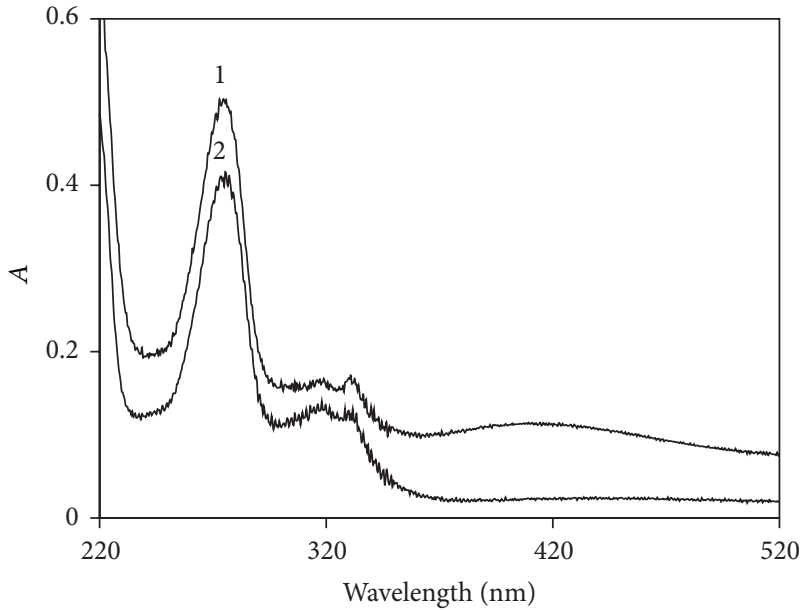

FIgURE 3: UV-vis absorption spectra. (1) Silver nanoparticles$\mathrm{Tb}$ (III)-PFLX; (2) $\mathrm{Tb}$ (III)-PFLX. Conditions: silver nanoparticles, $5.0 \times 10^{-6} \mathrm{M}$; Tb(III), $2.0 \times 10^{-4} \mathrm{M}$; PFLX, $1.0 \times 10^{-6} \mathrm{M}$.

interactions between $\mathrm{Tb}$ (III)-PFLX and silver nanoparticles and it can be concluded that silver nanoparticles incorporate with the complex of $\mathrm{Tb}(\mathrm{III})$-PFLX, while the particle aggregates are formed in the ternary complex [16].

3.2. Second-Order Scattering Spectra and Fluorescence Spectra. $\alpha$-Keto acid of PFLX supplies a coordination site binding to $\mathrm{Tb}(\mathrm{III})$ ion and has two aromatic rings that can absorb energy, resulting in intramolecular energy from PFLX to $\mathrm{Tb}$ (III) ions; thus, $\mathrm{Tb}(\mathrm{III})$ excited state is formed and then emits the characteristic emission of $\mathrm{Tb}$ (III), locating at 490 , 545,580 , and $620 \mathrm{~nm}$, corresponding to the transitions of the $\mathrm{Tb}$ (III) 5D4 $\rightarrow$ 7F6, 5D4 $\rightarrow$ 7 F5, 5D4 $\rightarrow$ 7F4, and 5D4 $\rightarrow 7 \mathrm{~F} 3$, respectively [36]. The maximum fluorescence peak locates at $545 \mathrm{~nm}$ when it is excited; the silver nanoparticles can enhance the fluorescence of $\mathrm{Tb}$ (III)-PFLX complex, especially at $545 \mathrm{~nm}$. At the same time, the SOS peak is also enhanced at $545 \mathrm{~nm}$ when the excited wavelength is at $273 \mathrm{~nm}$, so the intensities conclude the fluorescence and SOS intensity. Figure 4 shows the fluorescence and SOS spectra, and the UV-35 filter is added to eliminate the scattering of the system [37].

3.3. Comparison between Silver Nanoparticles-Tb(III)-PFLX and Silver Nanoparticles-Tb(III)-OFLX System. From the fluorescence-SOS spectra above, the difference between silver nanoparticles-Tb(III)-PFLX and silver nanoparticles$\mathrm{Tb}$ (III)-OFLX system could be observed (as shown in Figure 5). Silver nanoparticles can enhance the fluorescenceSOS intensity at $545 \mathrm{~nm}$ of Tb(III)-PFLX complex, while it can slightly increase the intensity of Tb(III)-OFLX system.

The observed spectral differences seem to be dependent on the structural variation of the fluoroquinolone and especially on the nature of the N1 substituent. The benzoxazine group of OFLX appears as an efficient electron-attracting system acting as a quencher of the fluorescence process. In

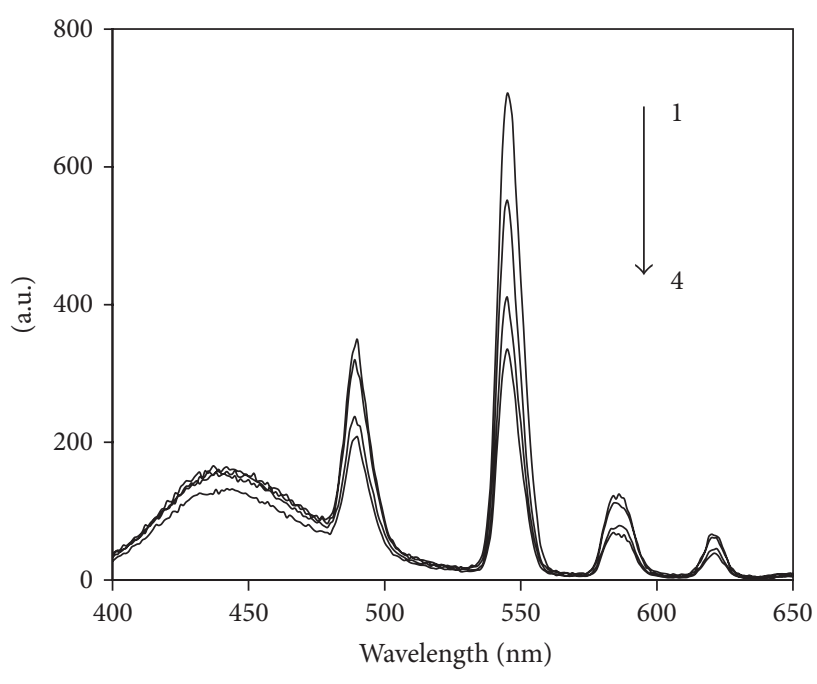

FIgURE 4: The fluorescence and second-order scattering spectra. (1) Silver nanoparticles-Tb(III)-PFLX (without filter), (2) silver nanoparticles-Tb(III)-PFLX (with filter), (3) Tb(III)-PFLX (without filter), and (4) $\mathrm{Tb}(\mathrm{III})-\mathrm{PFLX}$ (with filter); $\lambda_{\mathrm{ex}}=273 \mathrm{~nm}$. Conditions: silver nanoparticles, $5.0 \times 10^{-6} \mathrm{M}$; $\mathrm{Tb}(\mathrm{III}), 2.0 \times 10^{-4} \mathrm{M}$; PFLX, $1.0 \times 10^{-6} \mathrm{M}$.

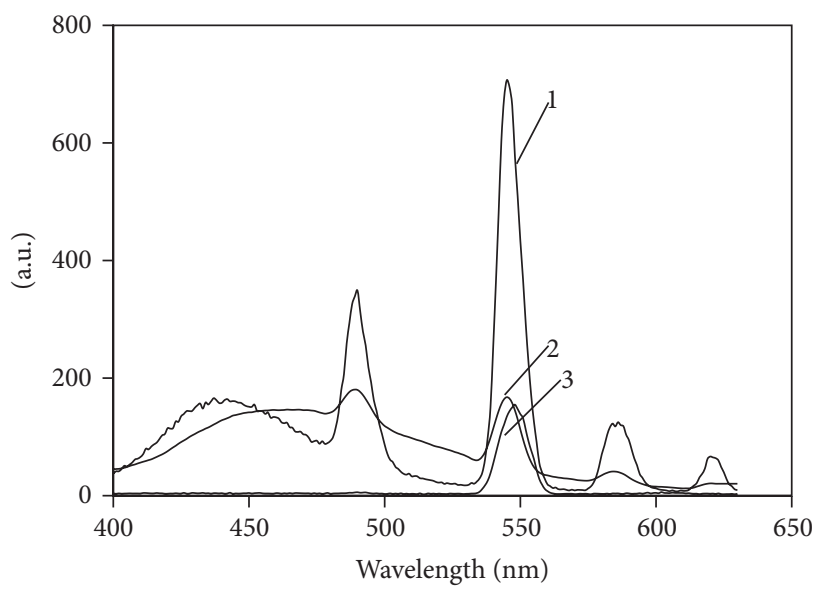

FIGURE 5: The fluorescence and second-order scattering spectra of PFLX and OFLX. (1) Silver nanoparticles-Tb(III)-PFLX, (2) silver nanoparticles-Tb(III)-OFLX, and (3) silver nanoparticles- $\mathrm{Tb}(\mathrm{III})$. Conditions: silver nanoparticles, $5.0 \times 10^{-6} \mathrm{M}$; Tb(III), $2.0 \times 10^{-4} \mathrm{M}$; PFLX and OFLX, $1.0 \times 10^{-6} \mathrm{M}$.

contrast, the PFLX system has strong intensity owing to the electron-donating character of the N1 ethyl substituent [38]. The molecular structures of PFLX and OFLX are shown in Figure 1.

On the other hand, according to the theory of "the trivial of radiative mechanism for electronic energy transfer" [39], the efficiency of energy transfer is related to the capability of absorbing photon $(\varepsilon)$ for donor and the overlap of the emission spectrum of donor and the absorption spectrum of acceptor. In $\mathrm{Tb}$ (III)-PFLX and $\mathrm{Tb}(\mathrm{III})-O F L X$ complexes, $\varepsilon_{\mathrm{PFLX}}>\varepsilon_{\mathrm{OFLX}}$, at the same time, the emission spectrum of 


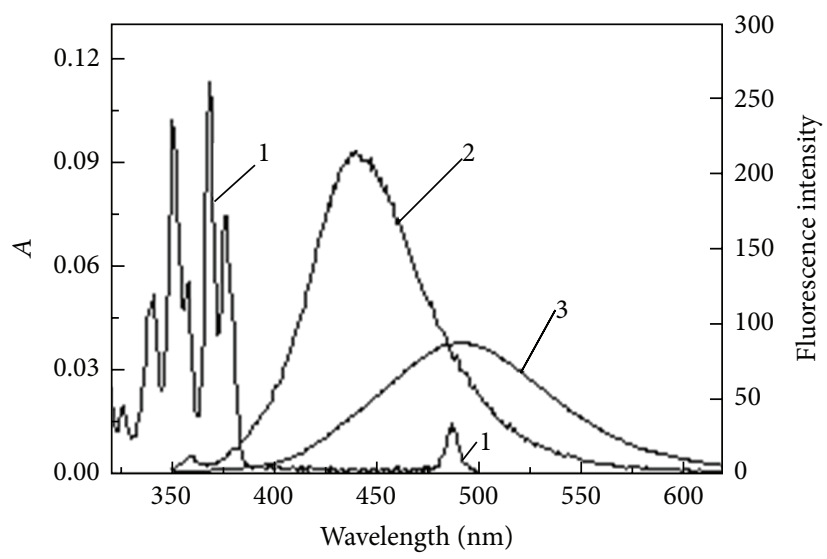

Figure 6: Absorption spectrum of Tb(III) (1) and emission spectra of PFLX (2) and OFLX (3) Conditions: Tb(III), $2.0 \times 10^{-4} \mathrm{M}$; PFLX and OFLX, $1.0 \times 10^{-6} \mathrm{M}$.

TABLE 1: Tolerance of coexisting substance ${ }^{\mathrm{a}}$.

\begin{tabular}{|c|c|c|c|c|c|}
\hline Substance & $\begin{array}{l}\text { Concentration } \\
\text { coexisting } \\
\left(\times 10^{-6} \mathrm{M}\right)\end{array}$ & $\begin{array}{c}\text { Intensity change } \\
(\%)\end{array}$ & Substance & $\begin{array}{c}\text { Concentration } \\
\text { coexisting } \\
\left(\times 10^{-6} \mathrm{M}\right)\end{array}$ & $\begin{array}{c}\text { Intensity change } \\
(\%)\end{array}$ \\
\hline Hemoglobin & $10^{\mathrm{b}}$ & +0.4 & $\mathrm{Fe}^{3+}, \mathrm{NO}_{3}^{-}$ & 10 & +3.4 \\
\hline Myoglobin & $1^{\mathrm{b}}$ & -0.1 & $\mathrm{Mg}^{2+}, \mathrm{SO}_{4}{ }^{2-}$ & 1000 & +2.4 \\
\hline Vitamin B1 & $5^{\mathrm{b}}$ & -4.7 & $\mathrm{NH}_{4}^{+}, \mathrm{Cl}^{-}$ & 10000 & +4.5 \\
\hline Glucose & $500^{\mathrm{b}}$ & +4.8 & $\mathrm{~K}^{+}, \mathrm{Cl}^{-}$ & 1000 & -1.3 \\
\hline Fructose & $500^{\mathrm{b}}$ & +4.4 & $\mathrm{Co}^{2+}, \mathrm{SO}_{4}{ }^{2-}$ & 100 & -1.1 \\
\hline Starch & $100^{\mathrm{b}}$ & +4.0 & $\mathrm{Na}^{+}, \mathrm{Cl}^{-}$ & 10000 & +4.6 \\
\hline$\beta$-alanine & $100^{\mathrm{b}}$ & -0.7 & $\mathrm{Mn}^{2+}, \mathrm{SO}_{4}{ }^{2-}$ & 1000 & +4.8 \\
\hline$\beta-\mathrm{CD}$ & $100^{\mathrm{b}}$ & +2.7 & $\mathrm{Cd}^{2+}, \mathrm{Ac}^{-}$ & 100 & -3.2 \\
\hline Uric acid & 5 & -2.6 & $\mathrm{Zn}^{2+}, \mathrm{SO}_{4}{ }^{2-}$ & 100 & -0.7 \\
\hline$\beta$-dextrin & 50 & +1.2 & $\mathrm{~Pb}^{2+}, \mathrm{NO}_{3}{ }^{-}$ & 100 & +1.9 \\
\hline $\mathrm{Al}^{3+}, \mathrm{SO}_{4}{ }^{2-}$ & 10 & +5.1 & $\mathrm{~K}^{+}, \mathrm{H}_{2} \mathrm{PO}_{4}^{-}$ & 10 & +4.1 \\
\hline $\mathrm{Ni}^{2+}, \mathrm{NO}_{3}^{-}$ & 10 & +3.0 & $\mathrm{Cr}^{3+}, \mathrm{Cl}^{-}$ & 100 & -4.0 \\
\hline $\mathrm{Cu}^{2+}, \mathrm{SO}_{4}{ }^{2-}$ & 10 & -4.9 & $\mathrm{Ca}^{2+}, \mathrm{Cl}^{-}$ & 1000 & +4.8 \\
\hline
\end{tabular}

${ }^{\mathrm{a}}$ Conditions: PFLX, $1.0 \times 10^{-6} \mathrm{M}$; $\mathrm{Tb}(\mathrm{III})$ ion, $2.0 \times 10^{-4} \mathrm{M}$; silver nanoparticles, $5.0 \times 10^{-6} \mathrm{M} ; \mathrm{pH}, 6.0 \times 10^{-6} \mathrm{~g} \mathrm{~mL}^{-1}$.

TABLE 2: Analytical parameters for the determination of PFLX.

\begin{tabular}{ccccc}
\hline & $\begin{array}{c}\text { Linear range } \\
\left(\times 10^{-7} \mathrm{M}\right)\end{array}$ & $\begin{array}{c}\text { Linear regression } \\
\text { equation } \\
\left(c \times 10^{-7} \mathrm{M}\right)^{\mathrm{a}}\end{array}$ & $r^{\mathrm{b}}$ & $\begin{array}{c}\operatorname{LOD}^{\mathrm{c}}(3 \sigma, \\
\left.\times 10^{-10} \mathrm{M}\right)\end{array}$ \\
\hline PFLX & $0.008 \sim 10.0$ & $\Delta I=7229.5 c-9.2828$ & 0.9991 & 2.5 \\
& $10.0 \sim 80.0$ & $\Delta I=4653 c+419.95$ & 0.9973 & \\
\hline
\end{tabular}

${ }^{\mathrm{a}} \Delta I$ is the enhanced intensity of SOS and fluorescence.

${ }^{\mathrm{b}}$ Correlation coefficient.

${ }^{\mathrm{c}}$ Detection limit.

PFLX has a larger overlap with the absorption spectrum of $\mathrm{Tb}$ (III) than that of OFLX (see Figure 6); thus the efficiency of energy transfer of $\mathrm{Tb}$ (III)-PFLX system is much higher than that of $\mathrm{Tb}$ (III)-OFLX system, resulting in notable difference between them when the silver nanoparticles are added.
3.4. Influence of $p H$. Fluorescence and SOS intensity of the system is $\mathrm{pH}$ dependent. The effect of $\mathrm{pH}$ was investigated over the range of 3.0-8.0, and the optimum $\mathrm{pH}$ is about 6.0. Then a HAc-NaAc buffer solution of $\mathrm{pH} 6.0$ with a concentration of $0.1 \mathrm{M}$ was found to be suitable for the measurements. Maybe the reason is that $\mathrm{Ac}^{-}$replaces $\mathrm{H}_{2} \mathrm{O}$ which quenches fluorescence of the $\mathrm{Tb}(\mathrm{III})$ complex and incorporates with $\mathrm{Tb}(\mathrm{III})$-PFLX complex [40].

3.5. Effect of Tb(III) Ion Concentration. The effect of $\mathrm{Tb}(\mathrm{III})$ ion concentration in the range from $1.0 \times 10^{-5}$ to $5.0 \times$ $10^{-4} \mathrm{M}$ on the analytical signal for the system was studied. As the concentration of $\mathrm{Tb}$ (III) ion increased, the relative intensity was enhanced; when the concentration was over $2.0 \times 10^{-4} \mathrm{M}$, the relative intensity remains constant. So a $\mathrm{Tb}$ (III) ion concentration of $2.0 \times 10^{-4} \mathrm{M}$ was selected for further research. 
TABLE 3: Results for the determination of PFLX in capsules $(n=5)$.

\begin{tabular}{|c|c|c|c|c|c|c|}
\hline \multirow{2}{*}{ Sample } & \multirow{2}{*}{ Labeled (mg) } & \multicolumn{2}{|c|}{ Amount found \pm R.S.D. $\%$} & \multirow{2}{*}{ Added $\left(\times 10^{-7} \mathrm{M}\right)$} & \multirow{2}{*}{ Found $\left(\times 10^{-7} \mathrm{M}\right)$} & \multirow{2}{*}{ Recovery \pm R.S.D (\%) } \\
\hline & & This method & UV-method & & & \\
\hline \multirow{3}{*}{ PFLX (capsule 1) } & \multirow{3}{*}{200.0} & \multirow{3}{*}{$200.4 \pm 3.6$} & \multirow{3}{*}{$197.2 \pm 1.2$} & 1.00 & 1.04 & $104.0 \pm 3.60$ \\
\hline & & & & 2.00 & 2.04 & $102.0 \pm 2.90$ \\
\hline & & & & 4.00 & 4.06 & $101.5 \pm 2.92$ \\
\hline \multirow{3}{*}{ PFLX (capsule 2) } & \multirow{3}{*}{200.0} & \multirow{3}{*}{$200.2 \pm 1.5$} & \multirow{3}{*}{$196.9 \pm 3.9$} & 6.00 & 6.10 & $101.7 \pm 2.46$ \\
\hline & & & & 8.00 & 8.20 & $102.5 \pm 3.63$ \\
\hline & & & & 10.00 & 9.88 & $98.8 \pm 3.92$ \\
\hline
\end{tabular}

TABLE 4: Analytical recoveries of PFLX in serum samples $(n=5)$.

\begin{tabular}{lccc}
\hline PFLX & $\begin{array}{c}\text { Added } \\
\left(\times 10^{-8} \mathrm{M}\right)\end{array}$ & $\begin{array}{c}\text { Found } \\
\left(\times 10^{-8} \mathrm{M}\right)\end{array}$ & $\begin{array}{c}\text { Recovery } \pm \text { R.S.D. } \\
(\%)\end{array}$ \\
\hline \multirow{3}{*}{ Serum 1 } & 1.00 & 1.03 & $103.0 \pm 3.21$ \\
& 2.00 & 2.03 & $101.5 \pm 3.89$ \\
& 3.00 & 3.02 & $100.7 \pm 4.53$ \\
\hline \multirow{3}{*}{ Serum 2 } & 3.00 & 3.12 & $104.0 \pm 3.96$ \\
& 5.00 & 4.79 & $95.8 \pm 2.43$ \\
& 7.00 & 6.92 & $98.8 \pm 3.36$ \\
\hline
\end{tabular}

3.6. Effect of Silver Nanoparticles Concentration. From the experiments, it can be inferred that not only the size but also the concentration of nanoparticles (namely, the numbers of particles in the unit volume) can affect the luminescence intensity of the system. The silver nanoparticles are prepared by $\mathrm{AgNO}_{3}$ solutions of $1.0 \times 10^{-3} \mathrm{M}, 1.0 \times 10^{-4} \mathrm{M}$, and $1.0 \times 10^{-5} \mathrm{M}$, respectively. The results show that if $\mathrm{AgNO}_{3}$ was $1.0 \times 10^{-3} \mathrm{M}$, the silver nanoparticles have very high SOS scattering and the relative intensity is not proportional to the concentration of drug; if $\mathrm{AgNO}_{3}$ is $1.0 \times 10^{-5} \mathrm{M}$, the scattering intensity of silver nanoparticles was very low and the fluorescence-SOS could not be enhanced by the silver nanoparticles. The silver nanoparticles are suitable for this system if $\mathrm{AgNO}_{3}$ is $1.0 \times 10^{-4} \mathrm{M}$ and the mean diameter is $42 \mathrm{~nm}$, and thus they are chosen in the experiments.

Fixing the size of silver nanoparticles mentioned above, the effects of the concentration on the intensity of SOS and fluorescence are also studied. A concentration of $5.0 \times 10^{-6} \mathrm{M}$ of silver nanoparticles is used for further experiments.

\section{Stability}

Under the optimum conditions, the results showed that $\Delta I$ reached a maximum after all reagents were mixed for $25 \mathrm{~min}$ and the intensity was stable for at least $3 \mathrm{~h}$, so that $25 \mathrm{~min}$ was set as the standard for all the SOS and fluorescence measurements.

4.1. Tolerance of Foreign Substances. In order to assess the possibility of analytical application of the method, the effects of some common excipients, metal ions, and organic compounds on signals intensity are investigated. The tolerable concentration ratios for the interference are $< \pm 5 \%$. The results are presented in Table 1 . It can be seen from Table 1 that most of metal ions can be allowed at higher concentrations, but some organic species such as myoglobin, Vitamin B1, and uric acid have a relatively high interference. In sample determinations, starch and dextrin which exist in capsules can be eliminated through filtration, while in the serum samples, $\mathrm{ZnSO}_{4}$ and $\mathrm{Ba}(\mathrm{OH})_{2}$ can be added in order to precipitate the interference before the determination [40]. So it can be successfully applied to determine PFLX in capsules and serum samples.

4.2. Calibration and Detection Limitation. The calibration graphs for the determination of PFLX are conducted under the optimal conditions, and the results are given in Table 2. The detection limit $(3 \sigma)$ is $2.5 \times 10^{-10} \mathrm{M}$ for PFLX.

4.3. Samples Determination. The proposed method is applied to the determination of PFLX in capsules and compared with UV-vis method; the results are given in Table 3. There are no significant differences between labeled contents and those obtained by this method. Recoveries range from $98.8 \%$ to $104.0 \%$.

Moreover, analytical recoveries were assessed by analyzing serum samples which contain PFLX and required only separation of the precipitated protein with centrifugation [41]. In order to make the sample concentrations of the drug within the linear range of the determination, serum samples were properly diluted and the recoveries were determined by the standard addition method [42]. The results are shown in Table 4.

\section{Conclusion}

The proposed silver nanoparticles sensitized fluorescence and SOS method for the determination of PFLX is simple, rapid, and could be easily automated. At the same time, this method shows high sensitivity and wide linear response for the determination of PFLX; the sensitivity of this method is higher than that of most other methods summarized in Table 5. Since nanoparticles have unique physical and 
TABLE 5: Common methods for the determination of PFLX.

\begin{tabular}{|c|c|c|c|}
\hline probe & Limit of determination $(3 \sigma)$ & Method of detection & Reference \\
\hline Water-soluble CdTe quantum dots & $1.3 \times 10^{-8} \mathrm{~g} / \mathrm{mL}$ & Fluorescence & {$[18]$} \\
\hline Terbium(III) & $3.2 \times 10^{-9} \mathrm{~g} / \mathrm{mL}$ & Fluorescence & [19] \\
\hline $\mathrm{La}(\mathrm{III})$ & $2.8 \times 10^{-9} \mathrm{~g} / \mathrm{mL}$ & Fluorescence & {$[20]$} \\
\hline $\mathrm{Ce}^{4+}-\mathrm{Na}_{2} \mathrm{SO}_{3}-\mathrm{H}_{2} \mathrm{SO}_{4}$ & $2.0 \times 10^{-8} \mathrm{~g} / \mathrm{mL}$ & Chemiluminescence & {$[21]$} \\
\hline SDS-Terbium(III) & $\begin{array}{c}3.0 \times 10^{-9} \mathrm{~mol} / \mathrm{L} \\
\left(1 \times 10^{-9} \mathrm{~g} / \mathrm{mL}\right)\end{array}$ & Fluorescence & {$[22]$} \\
\hline Charge-transfer reaction & $5.46 \times 10^{-6} \mathrm{~g} / \mathrm{mL}$ & Spectrophotometry & {$[23]$} \\
\hline Silver nanoparticle-Terbium(III) & $\begin{array}{c}2.5 \times 10^{-10} \mathrm{~mol} / \mathrm{L} \\
\left(0.8 \times 10^{-10} \mathrm{~g} / \mathrm{mL}\right)\end{array}$ & Fluorescence and second-order scattering & This paper \\
\hline
\end{tabular}

chemical properties, applications of nanoparticles in analytical chemistry are very potential. But the mechanism needs further study.

\section{Conflict of Interests}

No conflict of interests is involved in this paper.

\section{Acknowledgments}

The project is supported by the National Nature Science Foundation of China (20331010), and the author is thankful to Beijing Normal University for providing laboratory and computational facilities.

\section{References}

[1] V. A. Grover, J. Hu, K. E. Engates, and H. J. Shipley, "Adsorption and desorption of bivalent metals to hematite nanoparticles," Environmental Toxicology and Chemistry, vol. 31, no. 1, pp. 8692, 2012.

[2] A. De Giacomo, M. Dell'Aglio, A. Santagata, R. Gaudiuso, O. De Pascale, and P. Wagener, "Cavitation dynamics of laser ablation of bulk and wire-shaped metals in water during nanoparticles production," Physical Chemistry Chemical Physics, vol. 15, pp. 3083-3092, 2013.

[3] A. Ivask, O. Bondarenko, N. Jepihhina, and A. Kahru, "Profiling of the reactive oxygen species-related ecotoxicity of $\mathrm{CuO}, \mathrm{ZnO}$, $\mathrm{TiO}_{2}$, silver and fullerene nanoparticles using a set of recombinant luminescent Escherichia coli strains: differentiating the impact of particles and solubilised metals," Analytical and Bioanalytical Chemistry, vol. 398, no. 2, pp. 701-716, 2010.

[4] H. Wang, X. Qiao, J. Chen, and S. Ding, "Preparation of silver nanoparticles by chemical reduction method," Colloids and Surfaces A: Physicochemical and Engineering Aspects, vol. 256, no. 2-3, pp. 111-115, 2005.

[5] M.-M. Jose Luis, G.-M. Maria del Mar, G.-M. Francisco et al., "Catalysis and inactivation of tyrosinase in its action on odiphenols, o-aminophenols and o-phenylendiamines: potential use in industrial applications," Journal of Molecular Catalysis B: Enzymatic, vol. 91, pp. 17-24, 2013.

[6] S. J. Hayes, D. W. Knight, M. D. Menzies, M. O’Halloran, and W.-F. Tan, "An efficient furan synthesis using heterogeneous catalysis," Tetrahedron Letters, vol. 48, no. 43, pp. 7709-7712, 2007.
[7] F.-K. Liu, F.-H. Ko, P.-W. Huang, C.-H. Wu, and T.-C. Chu, "Studying the size/shape separation and optical properties of silver nanoparticles by capillary electrophoresis," Journal of Chromatography A, vol. 1062, no. 1, pp. 139-145, 2005.

[8] H. Y. Fu, D. R. Chen, and Z. P. Cai, "Fiber sensor systems based on fiber laser and microwave photonic technologies," Sensors, vol. 12, pp. 5395-5419, 2012.

[9] M. H. Ullah, K. Il, and C.-S. Ha, "Preparation and optical properties of colloidal silver nanoparticles at a high $\mathrm{Ag}^{+}$ concentration," Materials Letters, vol. 60, no. 12, pp. 1496-1501, 2006.

[10] C. P. Lai, N. Alan, O. Peter et al., "Energy-efficient colourless photonic technologies for next-generation DWDM metro and access networks," in Proceedings of the International Conference on Photonics in Switching (PS '12), September 2012.

[11] P. Tuthill, N. Jovanovic, S. Lacour et al., "Photonic technologies for a pupil remapping interferometer," in Optical and Infrared Interferometry II, vol. 7734 of Proceedings of SPIE, July 2010.

[12] C. Dong, Z. Yan, J. Kokx, D. B. Chrisey, and C. Z. Dinu, "Antibacterial and surface-enhanced Raman scattering (SERS) activities of $\mathrm{AgCl}$ cubes synthesized by pulsed laser ablation in liquid," Applied Surface Science, vol. 258, pp. 9218-9222, 2012.

[13] S. K. Mwilu, A. M. El Badawy, B. Karen et al., "Changes in silver nanoparticles exposed to human synthetic stomach fluid: effects of particle size and surface chemistry," Science of the Total Environment, vol. 447, pp. 90-98.

[14] S. Hegde, S. Kapoor, S. Joshi, and T. Mukherjee, "Selfassembly of Ag nanoparticle-biotin composites into long fiberlike microstructures," Journal of Colloid and Interface Science, vol. 297, no. 2, pp. 637-643, 2006.

[15] M. M. Oliveira, D. Ugarte, D. Zanchet, and A. J. G. Zarbin, "Influence of synthetic parameters on the size, structure, and stability of dodecanethiol-stabilized silver nanoparticles," Journal of Colloid and Interface Science, vol. 292, no. 2, pp. 429-435, 2005.

[16] H. Nabika and S. Deki, "Enhancing and quenching functions of silver nanoparticles on the luminescent properties of europium complex in the solution phase," Journal of Physical Chemistry B, vol. 107, no. 35, pp. 9161-9164, 2003.

[17] J. A. Jiménez, S. Lysenko, H. Liu, E. Fachini, and C. R. Cabrera, "Investigation of the influence of silver and tin on the luminescence of trivalent europium ions in glass," Journal of Luminescence, vol. 130, no. 1, pp. 163-167, 2010.

[18] Y. Zhao, L. J. Gao, X. H. Sun, and H. M. Chai, "Determination of pefloxacin mesylate by water-soluble CdTe quantum dots," 
Chinese Journal of Spectroscopy Laboratory, vol. 29, pp. 17491752, 2012.

[19] G. Z. Li and G. Z. Li, "Fluorescence characteristics of $\mathrm{Tb}^{3+}$ pefloxacin and its application," Chinese Rare Earths, vol. 6, pp. 21-23, 2002.

[20] G. Z. Li, Y. M. Liu, and G. Z. Li, "Study on fluorescence characteristics of Pefloxaein-La(III) complex and its application," Spetrooscopy and Spectral Analysis, vol. 24, pp. 1086-1088, 2004.

[21] R.-P. Wang, Y.-J. Wu, S.-M. Zhai, J.-J. Li, and W. Zheng, "Chemiluminescent determination of pefloxacin mesylate," Chinese Journal of Antibiotics, vol. 34, no. 6, pp. 383-384, 2009.

[22] L. Liao, X. M. Cao, L. M. Du, and H. Wu, "Determination of Pefloxaein by terbium(III) ion fluorescence probe sensitized by the surfaetant," Journal of Analytical Science, vol. 24, pp. 95-97, 2008.

[23] S. B. Zhang and H. H. Lin, "Spectrophotometric determination of pefloxacin mesylate based on the charge-transfer reaction," Huaxue Shi, vol. 31, pp. 625-627, 2009.

[24] C. J. Veiopoulou, P. C. Ioannou, and E. S. Lianidou, "Application of terbium sensitized fluorescence for the determination of fluoroquinolone antibiotics pefloxacin, ciprofloxacin and norfloxacin in serum," Journal of Pharmaceutical and Biomedical Analysis, vol. 15, no. 12, pp. 1839-1844, 1997.

[25] S. Swoboda, K. Oberdorfer, F. Klee, T. Hoppe-Tichy, H. von Baum, and H. K. Geiss, "Tissue and serum concentrations of levofloxacin $500 \mathrm{mg}$ agministered intravenously or orally for antibiotic prophylaxis in biliary surgery," Journal of Antimicrobial Chemotherapy, vol. 51, no. 2, pp. 459-462, 2003.

[26] V. F. Samanidou, C. E. Demetriou, and I. N. Papadoyannis, "Direct determination of four fluoroquinolones, enoxacin, norfloxacin, ofloxacin, and ciprofloxacin, in pharmaceuticals and blood serum by HPLC," Analytical and Bioanalytical Chemistry, vol. 375, no. 5, pp. 623-629, 2003.

[27] M. Ooishi and M. Miyao, "Antibiotic sensitivity of recent clinical isolates from patients with ocular infections," Ophthalmologica, vol. 211, no. 1, pp. 15-24, 1997.

[28] A. M. Beltagi, "Determination of the antibiotic drug pefloxacin in bulk form, tablets and human serum using square wave cathodic adsorptive stripping voltammetry," Journal of Pharmaceutical and Biomedical Analysis, vol. 31, no. 6, pp. 1079-1088, 2003.

[29] M. E. El-Kommos, G. A. Saleh, S. M. El-Gizawi, and M. A. Abou-Elwafa, "Spectrofluorometric determination of certain quinolone antibacterials using metal chelation," Talanta, vol. 60, no. 5, pp. 1033-1050, 2003.

[30] L. M. Du, H. Y. Yao, and M. Fu, "Spectrofluorimetric study of the charge-transfer complexation of certain fluoroquinolones with 7,7,8,8-tetracyanoquinodimethane," Spectrochimica Acta A: Molecular and Biomolecular Spectroscopy, vol. 61, no. 1-2, pp. 281-286, 2005.

[31] M. I. R. M. Santoro, N. M. Kassab, A. K. Singh, and E. R. M. Kedor-Hackmam, "Quantitative determination of gatifloxacin, levofloxacin, lomefloxacin and pefloxacin fluoroquinolonic antibiotics in pharmaceutical preparations by highperformance liquid chromatography," Journal of Pharmaceutical and Biomedical Analysis, vol. 40, no. 1, pp. 179-184, 2006.

[32] P.-L. Wang, Y.-L. Feng, and L. Chen, "Simultaneous determination of trace norfloxacin, pefloxacin, and ciprofloxacin by TLCfluorescence spectrodensitometry," Microchemical Journal, vol. 56, no. 2, pp. 229-235, 1997.

[33] Z. Yang, X. Wang, W. Qin, and H. Zhao, "Capillary electrophoresis-chemiluminescence determination of norfloxacin and prulifloxacin," Analytica Chimica Acta, vol. 623, no. 2, pp. 231237, 2008.

[34] C. Fierens, S. Hillaert, and W. Van den Bossche, "The qualitative and quantitative determination of quinolones of first and second generation by capillary electrophoresis," Journal of Pharmaceutical and Biomedical Analysis, vol. 22, no. 5, pp. 763772, 2000.

[35] P. C. Lee and D. Meisel, "Adsorption and surface-enhanced Raman of dyes on silver and gold sols," Journal of Physical Chemistry, vol. 86, no. 17, pp. 3391-3395, 1982.

[36] Z. Tieli, Z. Huichun, and J. Linpei, "Photochemical fluorescence enhancement of the terbium-lomefloxacin complex and its application," Talanta, vol. 49, no. 1, pp. 77-82, 1999.

[37] G. Z. Chen, X. Z. Huang, Z. Z. Zheng, J. G. Xu, and Z. B. Wang, Fluorescence Analysis Method, Science Press, Beijing, China, 1990 (Chinese).

[38] A. Rieutorda, L. Vazquezb, M. Soursaca et al., "Fluoroquinolones as sensitizers of lanthanide fluorescence: application to the liquid chromatographic determination of ciprofloxacin using terbium," Analytica Chimica Acta, vol. 290, pp. 215-225, 1994.

[39] N. J. Turro, Modern Molecular Photochemistry, Benjamin/ Cummings Publishing, 1978.

[40] E. E. DiBella, J. B. Weissman, M. J. Joseph, J. R. Schultz, and T. J. Wenzel, "Lanthanide ions as luminescent chromophores for liquid chromatographic detection," Journal of Chromatography A, vol. 328, pp. 101-109, 1985.

[41] Y. Huang, C. Zhang, X. Zhang, and Z. Zhang, "Chemiluminescence analysis of menadione sodium bisulfite and analgin in pharmaceutical preparations and biological fluids," Journal of Pharmaceutical and Biomedical Analysis, vol. 21, no. 4, pp. 817825, 1999.

[42] C. T. Kenner and K. W. Bush, Quantitative Analysis, Macmillan, New York, NY, USA, 1979. 

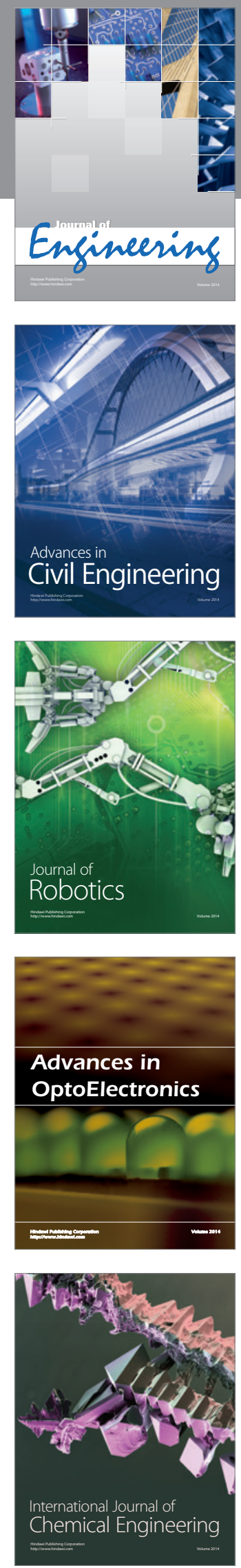

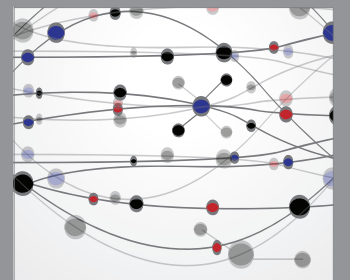

The Scientific World Journal
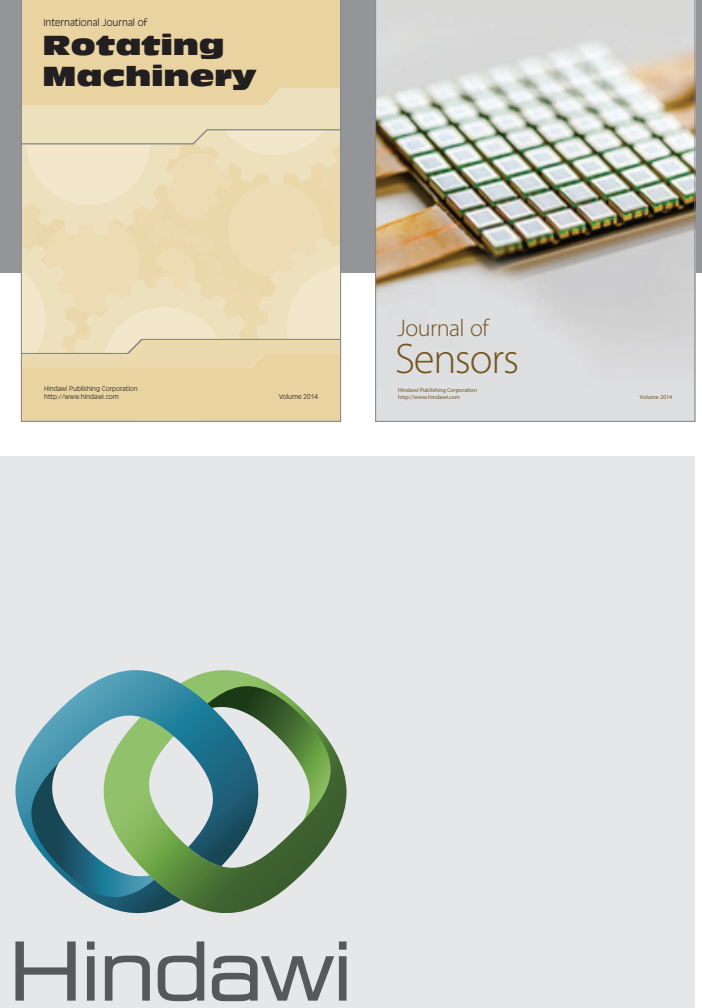

Submit your manuscripts at http://www.hindawi.com
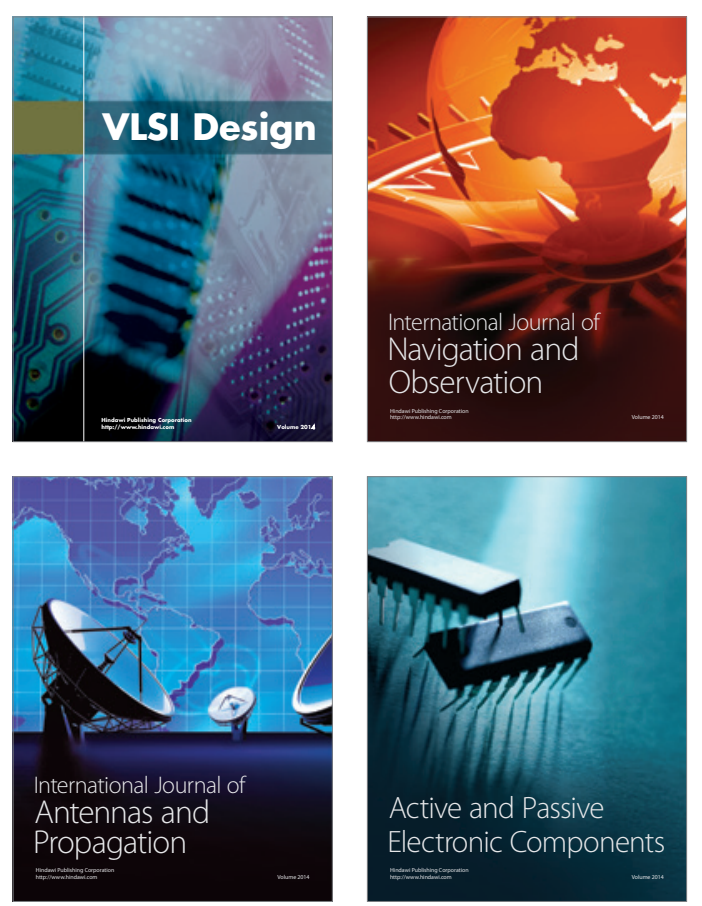
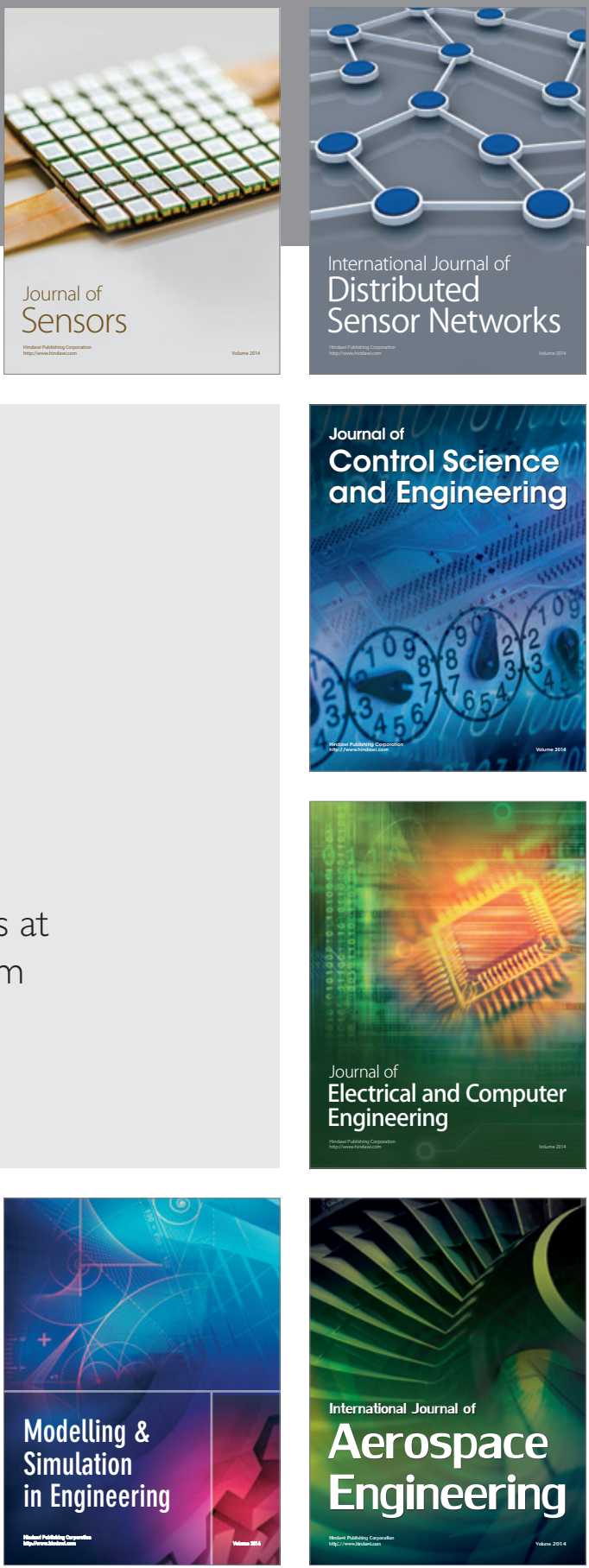

Journal of

Control Science

and Engineering
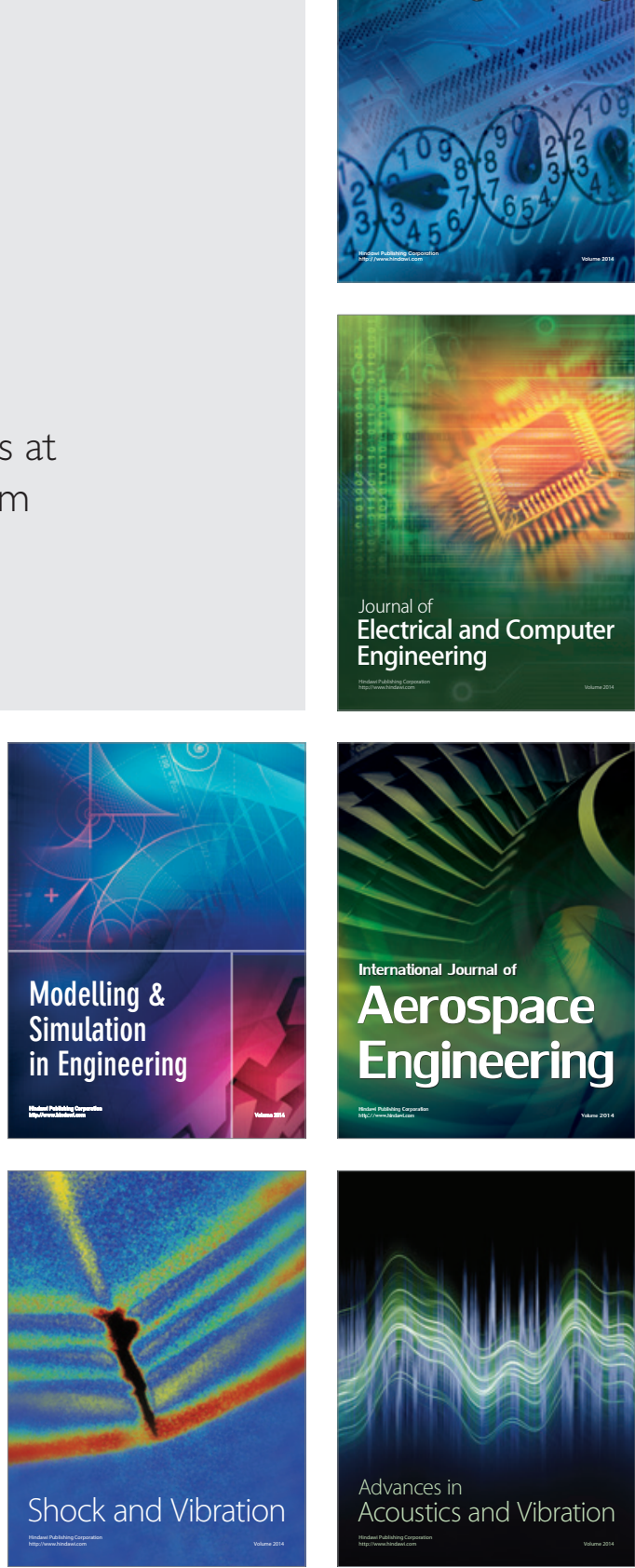